\author{
L. Peruzzi, S. Bagella, R. Filigheddu, B. Pierini, M. Sini, F. Roma-Marzio, \\ K. F. Caparelli, G. Bonari, G. Gestri, D. Dolci, A. Consagra, P. Sassu, M. \\ C. Caria, G. Rivieccio, M. Marrosu, M. D’Antraccoli, G. Pacifico, V. Piu \& \\ G. Bedini
}

\title{
The Wikiplantbase project: the role of amateur botanists in building up large online floristic databases
}

\begin{abstract}
Peruzzi, L., Bagella, S., Filigheddu, S., Pierini, B., Sini, M., Roma-Marzio, F., Caparelli, K. F., Bonari, G., Gestri, G., Dolci, D., Consagra, A., Sassu, P., Caria, M. C., Rivieccio, G., Marrosu, M., D’Antraccoli, M., Pacifico, G., Piu, V. \& Bedini, G.: The Wikiplantbase project: the role of amateur botanists in building up large online floristic databases. - Fl. Medit. 27: 117-129. 2017. - ISSN: 1120-4052 printed, 2240-4538 online.

The Wikiplantbase project, started in 2013, provides a framework where the full set of georeferenced floristic records of Tuscany and Sardinia can be entered, stored, updated and freely accessed through the Internet. Mainly thanks to the collaboration of amateur botanists, data have accumulated quickly. All records entered by collaborators are submitted to the project coordinators, who are enabled to accept, modify, or reject them. As of 22 November 2016, Wikiplantbase \#Toscana holds 116,402 verified floristic records (90\% based on published literature, $5 \%$ on unpublished herbarium specimens, $5 \%$ on field observations), and Wikiplantbase \#Sardegna 40,043 (77\% published literature, 18\% unpublished herbarium specimens, 5\% on field observations ). The records include over $90 \%$ of the specific and subspecific taxa known for Tuscany and about $70 \%$ - but rapidly growing - of those known for Sardinia. The most recorded species are Quercus ilex L. (Fagaceae) for Tuscany and Pistacia lentiscus L. (Anacardiaceae) for Sardinia. With minor software tweaking, the online platform Wikiplantbase might be adopted in other contexts, resulting in a well connected network of regional floristic databases suited to exploit the involvement - still largely untapped - of nonacademic collaborators, as advocated by citizen science.
\end{abstract}

Key words: citizen science, Italy, online platform, Sardinia, Tuscany.

\section{Introduction}

Online databasing of plant diversity data became one of the major issues in biodiversity informatics in recent years. An increasing number of databases is now available concerning nomenclature and taxonomy, herbarium specimens, invasive alien plant monitoring, plant traits, ecology, vegetation, chromosome numbers, plant rDNA sites, genome size,

* Extended and enriched version of the oral presentation given at the XV OPTIMA meeting in Montpellier, 6-11 June 2016. 
DNA sequences. On the contrary, there are still few publicly available databases storing detailed information on plant distribution, especially at local level. Floristic records provide baseline data for researches in plant biology, linking a certain systematic unit to the localities where it is known to occur. As printed sources - like e.g. floras - are quickly outdated, researchers must look for updated data in the scientific literature and herbarium specimens (Bedini \& al. 2016, and literature cited therein).

In consideration of this, in June 2013 we have started the project "Wikiplantbase \#Toscana" (Peruzzi \& Bedini 2015 onwards) to provide a framework where the full set of georeferenced floristic records of Tuscany can be entered, stored, continuously updated and freely accessed through the Internet (Bedini \& Peruzzi 2013). Mainly thanks to the collaboration of amateur botanists, in few months thousands of data accumulated (more than 4,000 floristic records in September 2013, 54,233 in September 2014, see Bedini \& al. 2014) and in the fall of year 2014 also "Wikiplantbase \#Sardegna" (Bagella \& al. 2015onwards) went online and was quickly populated with floristic records (Bagella \& al. 2015; Peruzzi \& al. 2015). Shortly after, the project data were merged in a single database, whilst maintaining two distinct web addresses for accessing the data for Tuscany and Sardinia. All records entered by collaborators are submitted to the project coordinators, who are enabled to accept, modify, or reject them. Based on the data stored in Wikiplantbase \#Toscana at the beginning of 2015, we officially presented our project to the international scientific community (Bedini \& al. 2016).

\section{Materials and methods}

Botanical nomenclature follows Conti \& al. (2005, 2007) and subsequent updates issued as "Notulae alla checklist della Flora vascolare Italiana" on Informatore Botanico Italiano from 2007 to 2015 and on Italian Botanist from 2016 onwards. Plant names are associated to higher taxa following Peruzzi (2010a) and APG IV (The Angiosperm Phylogeny Group, 2016). Names of herbaria follow Thiers (2007-onwards). Bibliographical references documenting floristic records in Italian regions, and covering the period 1950-2005, were obtained by Scoppola \& Magrini (2005).

Georeferenced toponyms were mostly obtained from public databases maintained online by Regione Toscana (http://sira.arpat.toscana.it/sira/Toponomastica/COMUNI.htm) and Regione Sardegna (http://webgis.regione.sardegna.it/ricercatoponimi/).

Data management is powered by the open source relational DBMS Postgresql version 8.3, installed on a server maintained by the IT services of Pisa University. The same server provides storage space for the whole system. The database was designed around the concept of floristic record, i.e. the association of a valid plant name to a point in time and space via an accepted documentation. An Entity-Relationship (ER) model (Chen 1976) was developed to describe floristic records - so as to find an acceptable trade-off between the reduction of data redundancy and the practical management of database tables - and then used as a blueprint to create database tables.

The interface was written with custom HTML, CSS, Javascript and PHP coding, with the aim to provide easy and fast access to data and a practical, reliable procedure for entering new data. Georeferenced records are mapped to Google Maps. As Google Maps accepts only WGS84 coordinates, while the Postgresql version used in the project supports 
only plane coordinates, a software conversion from geographic to metric systems and viceversa was performed via proj4php, a library providing a PHP class for geographic coordinates transformation using proj4 definitions (https://github.com/proj4php/proj4php).

Critical issues about the interface design were discussed in public conferences and solved based on the recommendations and suggestions stemming from the discussion. Further suggestions were provided directly by collaborators after the start of the project, based on the experience gained while entering floristic records in Wikiplantbase.

Access to interface is provided through the project's website.

The number of site visitors is monitored through Google Analytics.

\section{Results}

\section{Data structure and interface}

The logical ER scheme is shown in Fig. 1.

The data are stored in seven tables, linked via 0:m or 1:m relationships and are arranged in three groups:

1. Georeferenced floristic records: two tables are included here, linked by a 0:m relationship connecting one record of "georeferenced toponyms" to one or many records of "floristic records". This relationship allows each floristic record to be unequivocally georeferenced. The tables are constantly updated by project collaborators via the web interface.

2. Taxonomic database: three tables provide updated plant names in a taxonomic framework. Note the recursive relationship of "plant_names", modelling synonyms and included names. The database is constantly updated by one of us (L. Peruzzi) via a dedicated interface. The taxonomic database is connected to floristic records via a 0:n relationship.

3. Bibliographic database: two tables provide bibliographical lists arranged by region of interest. The tables are constantly updated by project collaborators via the web interface.

Before going online, the tables "plant_names", "bibliographical_references", and "toponyms" were populated with data sourced as shown in Table 1, and were then added to as indicated above.

We developed thirteen interface pages to access different functions of the project, as shown in Table 2. Most pages are public except data entry pages - open to registered collaborators only - and data verification page, open solely to qualified system administrators. Taxonomic tables are updated via a separate interface type, not accessible from Wikiplantbase pages.

Besides the standard searches and reports accessible from the interface through the search, stats, and record density pages, further searches can be run by the database managers through the standard database front-end software - in this case psql - providing a native interface to the database via SQL.

Drop-down menus, autocomplete fields, and radio buttons are implemented in search and data entry pages to enhance ease of use by minimizing the number of keystrokes required to insert a new record or to look for stored records. The current layout of the interface results from the stimulating discussion raised in public conferences (held in Rosignano Marittimo (LI), 15 June 2013; Pisa, 30 April 2015) and from subsequent interaction with users. Therefore, in the data entry page, default values are provided in as many 


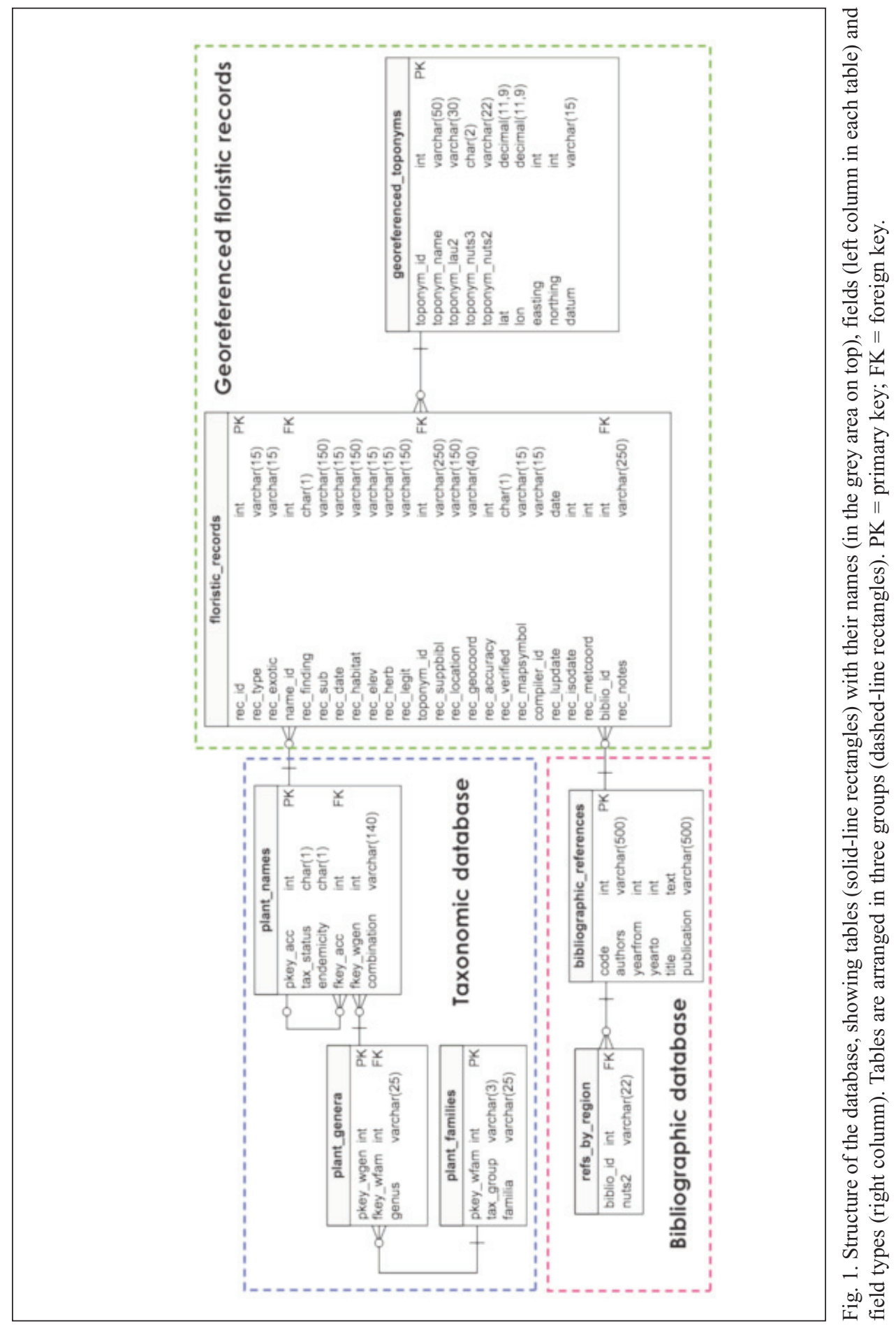


fields as practical, based on the commonest value for the field; while performing sequential data entry operation, data are carried over in most fields from previously inserted values; plant names and bibliographic references can be entered by typing the first four letters and then selecting from an autocomplete list; georeferencing can be accomplished just by clicking on a map, triggering the automatic fill-in of coordinates, nearest toponym, municipality (lau-2), and province (nuts-3) fields.

When users click on the "Record data" button, fields are checked for syntax and a message is displayed should any issue arise at this stage; if check is passed, data are recorded in the database along with user's credentials and a confirmation message is displayed.

All records are submitted to validation by a project editor prior to being admitted online. Editors are empowered to change items, especially the accepted name for the record. Collaborators in fact do not need to enter an accepted name, but are requested to enter a "sub" name either chosen from an autocomplete list linked with the "plant_names" table or manually typed in the field. In the first case, the accepted name field will be automatically filled, while in the second case it will be left blank: in this case, users can choose a name from an autocomplete list or leave the field blank. The accepted name field cannot be filled with free typing, but only by selecting from a list.

\section{Public engagement}

Besides four academic editors, sixty-five collaborators are currently registered in the project, mostly non-academic. They have provided a continuous input to the database since its inception.

While some collaborators are not yet active (i.e. have not yet entered records in the database), the contributions of active collaborators range from 1 to 41,964 records (mode $=$ 180). Besides data, collaborators have contributed valuable feedback about the interface; in some instances, they have pointed out unresponsive or erratic procedures at data entry or search page that needed to be fixed; in others, their suggestions were instrumental in streamlining data entry and improving the search page of Wikiplantbase. In the data entry page, users' suggestions focused on the procedures to enter a plant name, the record location, and the associated bibliographic reference. Experienced users are now able to enter up to two records per minute.

Four events were organized to disseminate Wikiplantbase to actual and potential collaborators as well as to people with a generic interest to know about Wikiplantbase:

- Rosignano Marittimo (15 June 2013, Wikiplantbase \#Toscana: verso un catalogo collaborativo, online e gratuito delle piante vascolari di Toscana)

- Pisa (30 April 2015, La nuova versione di Wikiplantbase \#Toscana in vista del traguardo delle 100000 segnalazioni: nuove potenzialità per l'inserimento e l'analisi dei dati)

- Sassari (25 November 2015, Piant@Là)

- Monte San Savino (24 luglio 2016, Wikiplantbase \#Toscana in azione. Un'escursione alla scoperta della flora vascolare dell'unico "punto bianco" di Wikiplantbase \#Toscana. See D’Antraccoli \& al. (2016)

Wikiplantbase is connected with two Facebook pages, one for Wikiplantbase \#Toscana ("Flora della Toscana"), one for Wikiplantbase \#Sardegna ("Flora della Sardegna"), enabling an informal interaction with collaborators and the general public.

In addition, the most active collaborators have been involved in the drafting of papers, including the present one. 


\section{Floristic records}

As of 22 November 2016, Wikiplantbase holds 156,872 floristic records for Tuscany and Sardinia, and approximately as many records in the ancillary tables "plant_names", "bibliographical_references", "toponyms".

The records for Tuscany include 3,958 specific and subspecific taxa, 1,044 genera and 158 families, referring to a total of 6,930 distinct localities and 808 bibliographic references; by taking into account only "presence" and "doubtful" records (therefore discarding "exclusion" records) of native and exotic taxa (therefore excluding cultivated plants), the number of specific and subspecific taxa drops to 3909, still over $95 \%$ of the specific and subspecific taxa known for Tuscany (Pierini \& Peruzzi 2014). As regards Sardinia, the records include 2001 specific and subspecific taxa, 660 genera and 128 families, referring to a total of 2,219 different localities and 134 bibliographic references. After selecting presence and doubtful records of native and exotic taxa, the taxonomic coverage is still about $68 \%$, based on Peruzzi (2010b).

The provinces hosting the highest number of floristic records are Grosseto (for Tuscany) and Sassari (for Sardinia) (Fig. 2a, b). In June 2016, a new function was added which

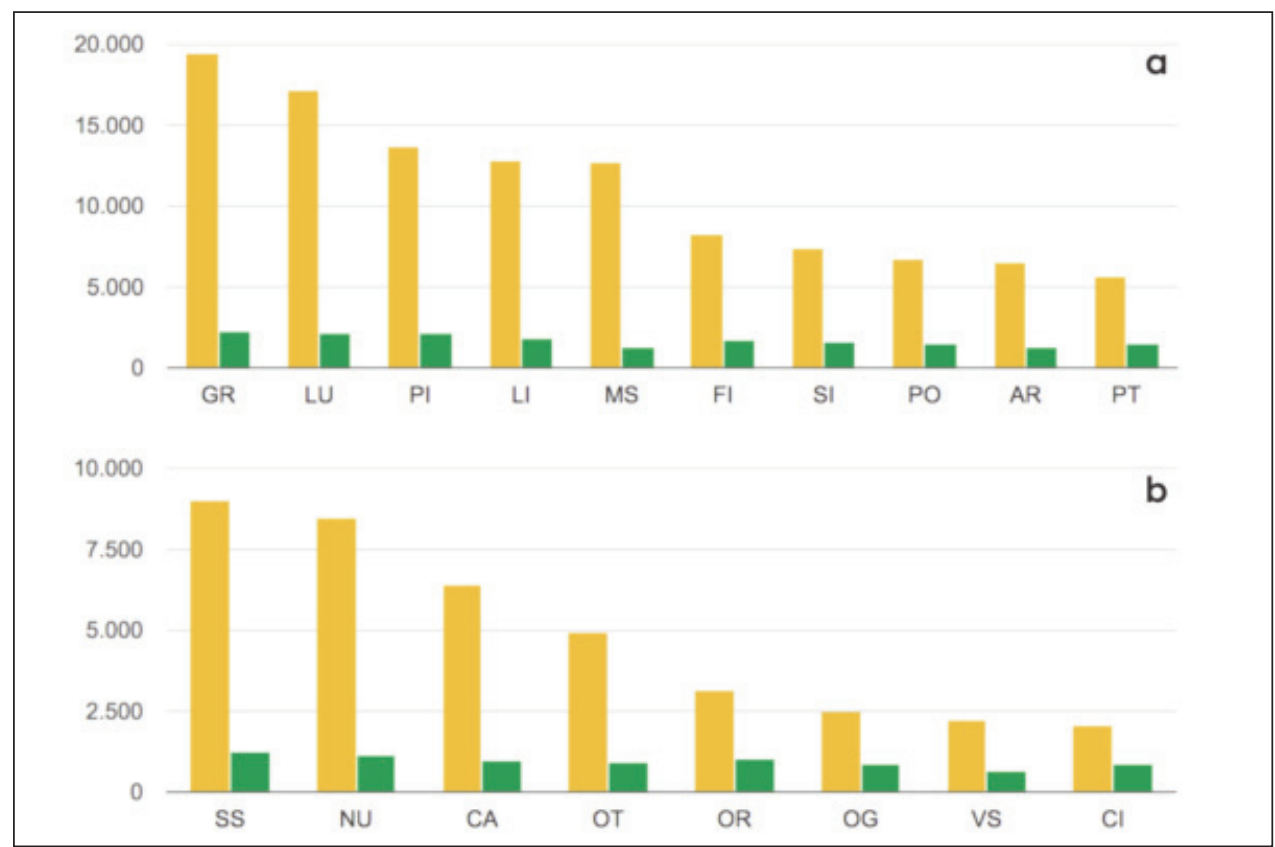

Fig. 2. Number of floristic records (orange bars) and species/subspecies (green bars) per administrative province in Tuscany (a) and Sardinia (b), as of 5 October 2016. GR = Grosseto; LU = Lucca; PI = Pisa; MS = Massa Carrara; LI = Livorno; FI = Firenze; $\mathrm{SI}=$ Siena; $\mathrm{PO}=$ Prato; $\mathrm{AR}=$ Arezzo; PT $=$ Pistoia SS $=$ Sassari NU $=$ Nuoro $; \mathrm{CA}=$ Cagliari OT $=$ Olbia-Tempio $; \mathrm{OR}=$ Oristano OG $=$ Ogliastra; VS = Medio Campidano; CI = Carbonia-Iglesias. The updated graphs can be obtained in real time from the webpages http://bot.biologia.unipi.it/wpb/toscana/stats.html and http://bot.biologia.unipi.it/wpb/sardegna/stats.html, respectively. 
allows the elaboration - in real time - of a map showing the sampling intensity (in terms of floristic records) for each municipality of the regions. All 280 municipalities in Tuscany have at least one floristic record (Fig. 3), while in Sardinia there are still many municipalities to fill with records (Fig. 4).

Stored floristic records in both regions are based on published literature (about $90 \%$ in Tuscany, $77 \%$ in Sardinia), herbarium specimens (about 5\% in Tuscany, $18 \%$ in Sardinia), and unpublished field observations (about 5\% in both regions) (Fig. 5a, b). The most recorded species are Quercus ilex L. (Fagaceae) for Tuscany (427 records from 283 distinct localities; Fig. 5), and Pistacia lentiscus L. (Anacardiaceae) for Sardinia (333 records from 217 different localities; Fig. 6a, b).

Starting from their availability online, Wikiplantbase pages have been visited 41,979 times by approximately 2800 visitors from 13 countries.

\section{Discussion}

The online platform Wikiplantbase is providing a framework where the full set of georeferenced floristic records of Tuscany can be entered, stored, continuously updated and freely accessed through the Internet. While other platforms exist to store biodiversity occurrence data, Wikiplantbase proved to be a very effective tool in this respect. Indeed, a query on plant records run on GBIF (www.gbif.org) returned 3,364 records in a polygon drawn around Tuscany borders and 5,665 around Sardinia, i.e. two and one order of magnitude - respectively - lower than Wikiplantbase for the same territories. Another Italian project, An Archive for Botanical Data (Lucarini \& al. 2015), gives free online access to floristic records obtained from 113,457 herbarium specimens and 34,542 relevés in the whole country, mostly related to central Italy. Unfortunately, its interface does not allow to extract the full occurrence data on a regional basis, so that it cannot be directly compared with Wikiplantbase project. However, in terms of order of magnitude, the two systems seem to stand on the same level, but Wikiplantbase achieved this result in a much shorter time span, considering that An Archive was started in 2000 (Lucarini \& al. 2015), Wikiplantbase in 2013, mainly thanks to the commitment of the project collaborators.

So far, most records come from published literature. This source impacts the overall quality of the stored data, which is about as good as that of the original papers, mostly subjected to peer-review, and books. Another significant source of data is represented by herbarium specimens, whose labels have been transcribed with no change except taxonomic updates if needed - but in any case, keeping also the original name. Field observations are a minor component of the database; while otherwise undocumented, observations records are carefully checked by the editors at validation step. In doubtful cases, they can request more information to contributors as an aid to their decision to accept or reject the record.

The fast rate of data entry is likely due to the care exerted in designing the user interface, aimed at reducing as far as possible and practical the number of keystrokes required to complete data entry for a floristic record. This design has been appreciated by collaborators, including those who were not accustomed to work with online databases and those who were outright uneasy with filling up an online form. While the user-friendly interface 


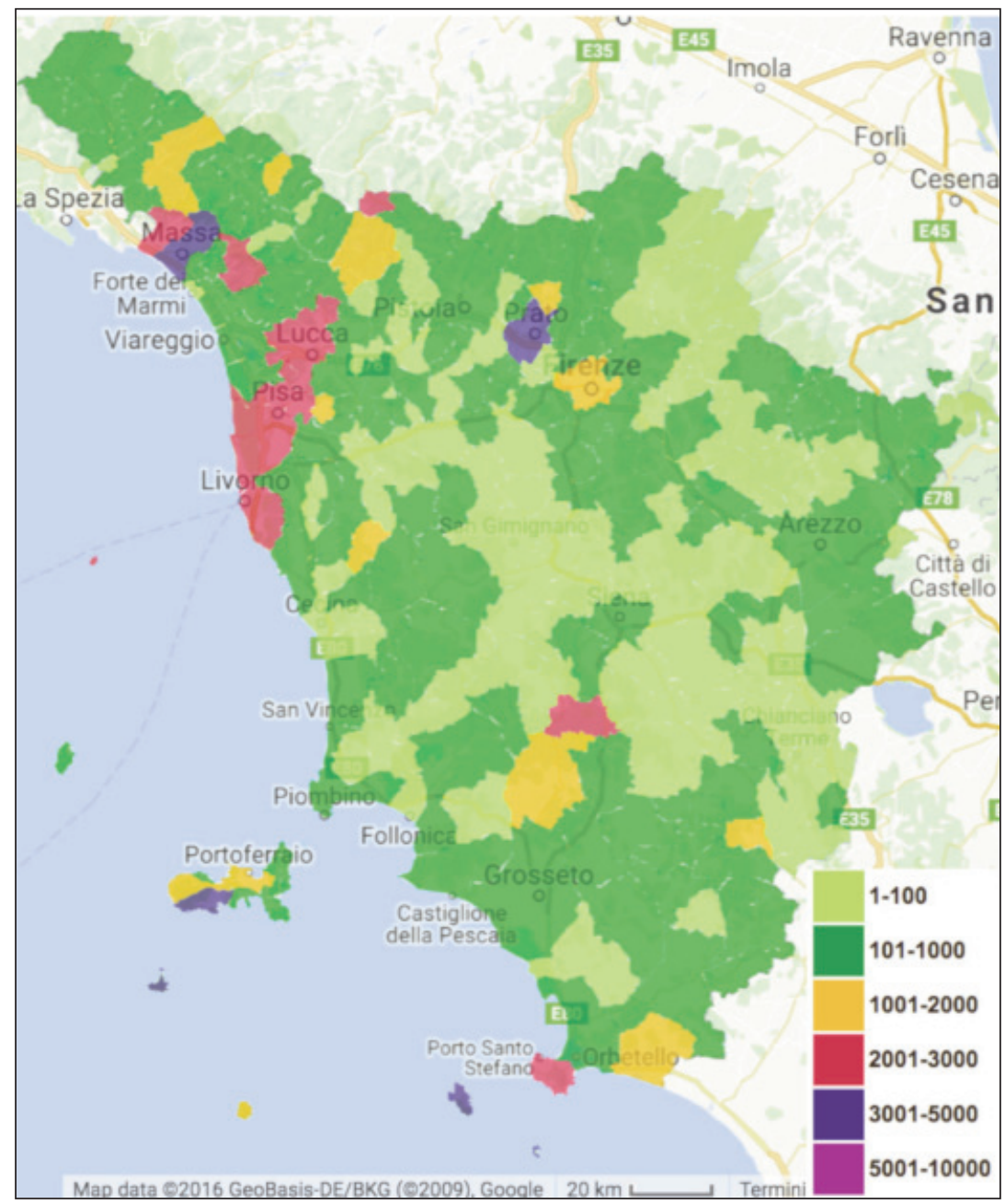

Fig. 3. Sampling intensity (in terms of floristic records) for each municipality of Tuscany, as of 5 October 2016. The different colors in the legend on the right refer to different range numbers of floristic records. The updated map can be obtained in real time from the webpage http://bot.biologia.unipi.it/wpb/toscana/dens_segn.html.

design is a bonus for data entry operators, it is also an effortless way to increase data integrity and semantic coherence. In this context, we were especially concerned about the correct use of plant names and solved the issue by enforcing a selection from a closed list of correct plant names - linked to the "plant_names" table - to fill the accepted name field. As the list in plant_names is constantly updated by the editors, its integrity and taxonomical coherence is ensured upstream of data entry and no responsibility about it is left with users. The selection from closed lists is enforced also in toponym and bibliographical ref- 


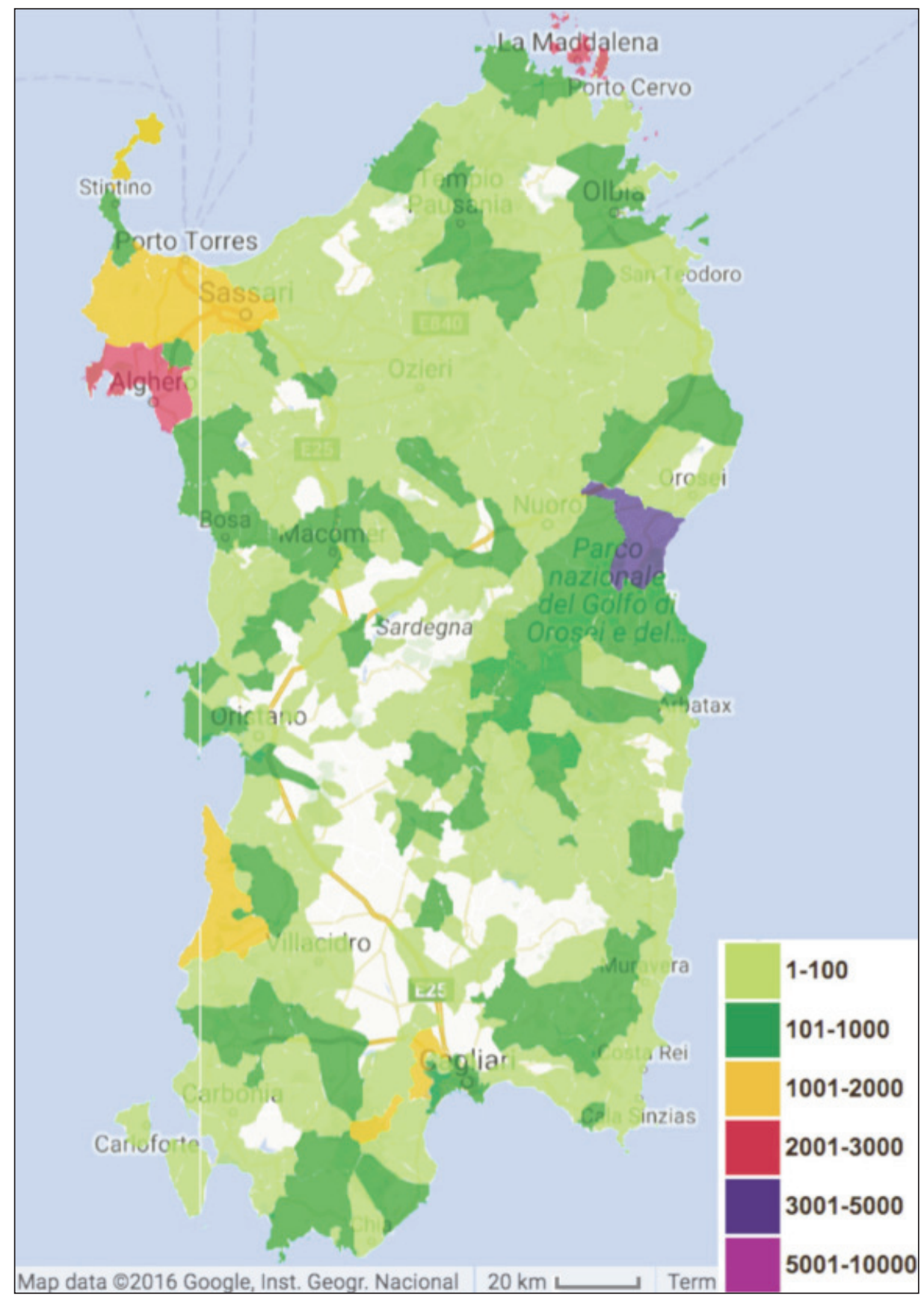

Fig. 4. Sampling intensity (in terms of floristic records) for each municipality of Sardinia, as of 5 October 2016. The different colors in the legend on the right refer to different range numbers of floristic records. The updated map can be obtained in real time from the webpage http://bot.biologia.unipi.it/wpb/sardegna/dens_segn.html. 

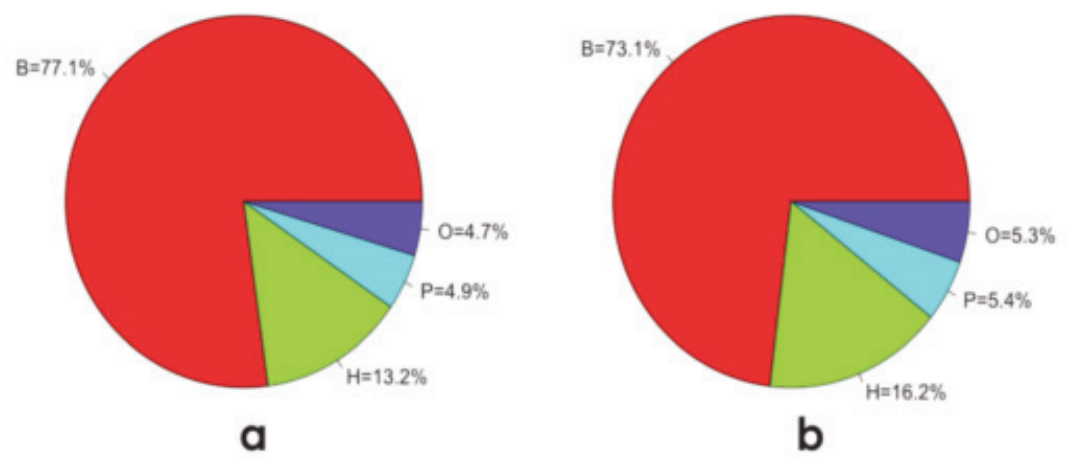

Fig. 5. Typology of floristic records stored in the databases for Tuscany (a) and Sardinia (b), as of 5 October 2016. $\mathrm{O}$ = field observations; $\mathrm{P}=$ published herbarium records; $\mathrm{B}=$ bibliographic records; $\mathrm{H}=$ unpublished herbarium records. The updated graphs can be obtained in real time from the webpages http://bot.biologia.unipi.it/wpb/toscana/stats.html and http://bot.biologia.unipi.it/wpb/sardeg$\underline{\text { na/stats.html, respectively. }}$

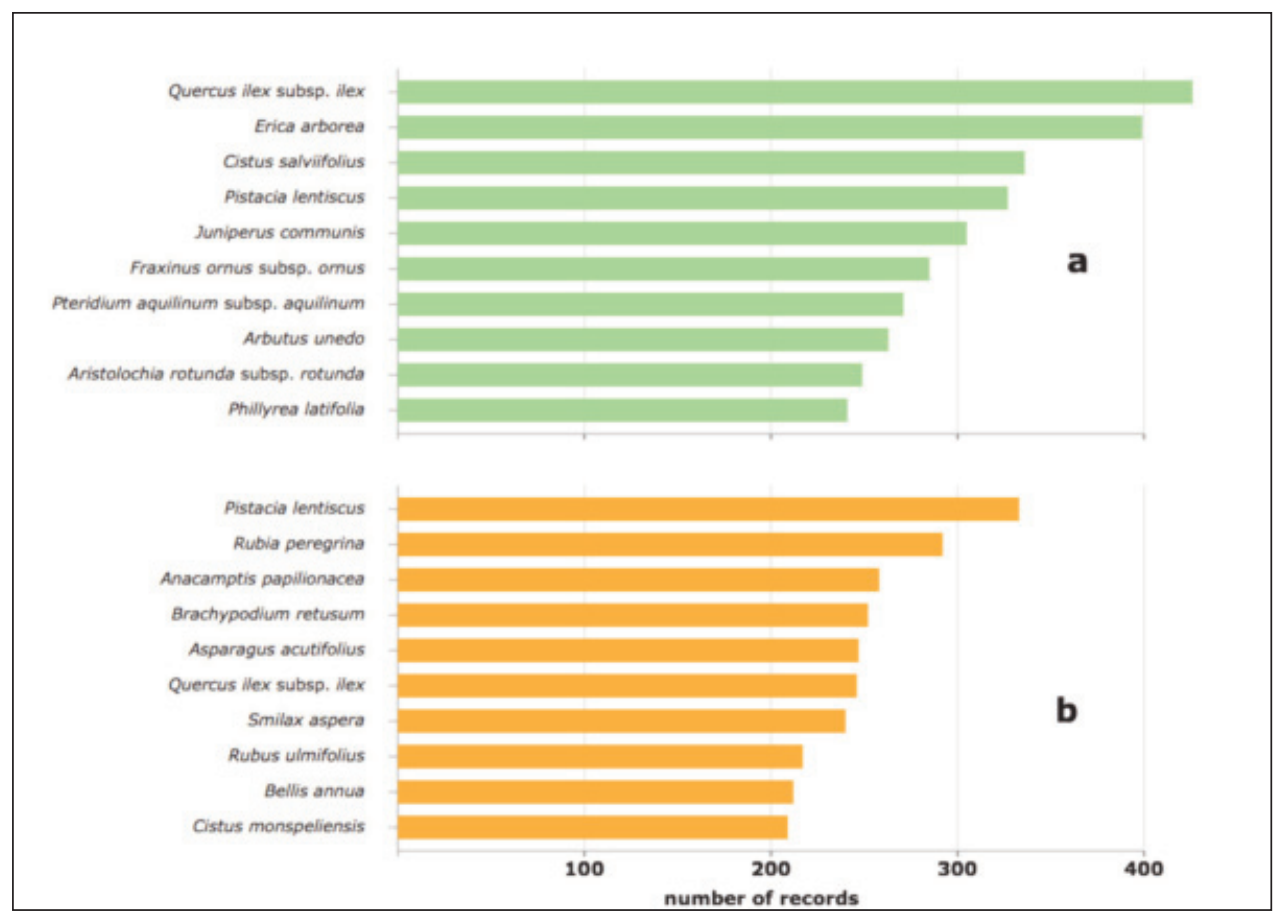

Fig. 6. The ten most recorded species/subspecies in Tuscany (a) and Sardinia (b), as of 5 October 2016. The updated graph can be obtained in real time from the webpage http://bot.biologia.unipi.it/wpb/toscana/stats.html and http://bot.biologia.unipi.it/wpb/sardegna/stats.html, respectively. 
erence fields, for the sake of limiting keystrokes and syntactical / semantical errors. Although desirable, this feature comes with a major drawback: if a plant name, a toponym or a bibliographical reference is not included in the list, the appropriate fields cannot be filled and any attempt to record the data will be rejected.

To overcome this hurdle, specific pages have been added for collaborators, where they can add the missing data using appropriate forms and controls, except for plant names as mentioned above.

After about three years of use, feedbacks and adjustments, data entry is now in a mature stage and does not seem to need any major revision. The public search interface, on the other hand, might benefit from several new features, as suggested by users, including:

1. export search results as csv or other formats;

2. query the database by clicking on a map, to retrieve records within a given radius from any point in the map or within a polygon drawn by users;

3. query the database by sending an SQL string, to provide competent users with full flexibility in searching the database, beyond the standardized search types available in the interface.

4. connection with taxon-oriented databases, to integrate taxonomic information and distribution data.

5. integration in large biodiversity data portals such as GBIF (www.gbif.org).

Some of the above points are already in a preliminary phase: as regards item 4, a static link to the taxon-oriented database Acta Plantarum (2007 onward-a) has been added in the homepage of Wikiplantbase and a dynamic link to Acta Plantarum search page has been added to the info window that appears upon clicking on the map symbols representing the records retrieved in a search operation; furthermore, Wikiplantbase is now enabled to accept queries from Acta Plantarum species pages (Acta Plantarum, 2007 onward-b), to power an effective two-way connection between the two systems.

As regards item 5, the connection with BIOCASE and GBIF is now in the testing stage and should go online by the end of 2016 to make Wikiplantbase records accessible through a BIOCASE web service.

In conclusion, Wikiplantbase's current design is the result of iterative interaction with a wide base of mostly non-academic collaborators willing to share their time and passion in a common project. Through subsequent refinements, Wikiplantbase is now a user-friendly system allowing people to feel comfortable about entering data; in turn, this resulted in a fast rate of data entry. Furthermore, Wikiplantbase is designed to be easily adopted in other contexts, resulting in a well-connected network of regional floristic databases suited to exploit the involvement - still largely untapped - of non-academic collaborators, as advocated by citizen science. Indeed, while contacts have been made to extend the project to Liguria, Sicily, any other Italian and foreign territory will be welcome. Given the fast rate of data entry, we foresee Wikiplantbase to furnish a substantial contribution to the floristic knowledge of several Italian territories.

\section{Acknowledgements}

We gratefully acknowledge other collaborators to the project: Angelino Carta, Giovanna Becca, Giuseppe Cataldi, Daniela Ciccarelli, Daniela Cinus, Roberto Dell'Orso, Eraldo Bocca, Ilaria Fozzi, 
Silvia Frasconi, Marco La Rosa, Ugo Macchia, Maria Magni, Alessandra Manca, Manuela Manca, Mairo Mannocci, Antonino Messina, Massimo Mirabile, Gian Battista Pau, Stefania Pisanu, Pier Paolo Roggero, Ivo Rossetti, Alessandro Niedda, Alessandra Sani, Veronica Sanna, Marco Sarria, Duccio Tampucci, Malvina Urbani, Antonio Zambrini. This paper was derived from an oral presentation within the symposium "The role of amateur networks in Mediterranean botany" of the XV OPTIMA Meeting, Montpellier, organised by Prof. J. Mathez.

\section{References}

Acta Plantarum 2007 onward-a: Progetto open source finalizzato allo studio della Flora spontanea d'Italia. http://www.actaplantarum.org (accessed on 15 October 2016).

- 2007 onward-b: IPFI, Indice dei nomi delle specie botaniche presenti in Italia. Disponibile on line (accessed on 15 October 2016): http://www.actaplantarum.org/flora/flora.php

Bagella, S., Caria, M.C., Bedini, G., Peruzzi, L., Sini, M. \& Filigheddu, R. 2015: The vascular flora of Mediterranean temporary wetlands in Wikiplantbase \#Sardegna. - P. 34 in: Pisanu, S. \& Bagella, S. (Eds.) International Symposium on Mediterranean Temporary Ponds. Book of abstracts. - Sassari.

—, Filigheddu, R., Peruzzi, L. \& Bedini, G. (Eds.) 2015-onwards: Wikiplantbase \#Sardegna v. 2.1. - Available from: http://bot.biologia.unipi.it/wpb/sardegna/index.html (accessed 1 June 2016).

Bedini, G. \& Peruzzi, L. 2013: Wikiplantbase \#Toscana - verso un catalogo collaborativo, online e gratuito delle piante vascolari di Toscana. - Pp. 25-26 in: Peccenini, S. \& Domina, G. (Eds.), Contributi alla ricerca floristica in Italia. - Firenze.

—, Pierini, B., Roma-Marzio, F., Caparelli, K. F., Dolci, D., Gestri, G. \& Peruzzi, L. 2014: Wikiplantbase \#Toscana, breaking the dormancy of floristic data. - P. 32 in Anonymous (Eds.) I International Plant Science Conference - $109^{\circ}$ Congresso della Società Botanica Italiana, 25 September 2014, Florence.

—, —, —, —, Bonari, G., Dolci, D., Gestri, G., D’Antraccoli, M. \& Peruzzi, L. 2016: Wikiplantbase \#Toscana, breaking the dormancy of floristic data. - P1. Biosyst. 150(3): 601-610. doi:10.1080/11263504.2015.1057266.

Chen, P. 1976: The Entity-Relationship Model - Toward a Unified View of Data. - ACM Trans. Database Syst. 1(1): 9-36. doi:10.1145/320434.320440.

Conti, F., Abbate, G., Alessandrini, A. \& Blasi, C. 2005: An annotated checklist of the Italian vascular flora. - Roma.

-, Alessandrini, A., Bacchetta, G., Banfi, E., Barberis, G., Bartolucci, F., Bernardo, L., Bonacquisti, S., Bouvet, D., Bovio, M., Brusa, G., Del Guacchio, E., Foggi, B., Frattini, S., Galasso, G., Gallo, L., Gangale, C., Gottschlich, G., Grünanger, P., Gubellini, L., Iiriti, G., Lucarini, D., Marchetti, D., Moraldo, B., Peruzzi, L., Poldini, L., Prosser, F., Raffaelli, M., Santangelo, A., Scassellati, E., Scortegagna, S., Selvi, F., Soldano, A., Tinti, D., Ubaldi, D., Uzunov, D. \& Vidali, M. 2007: Integrazioni alla Checklist della flora vascolare italiana. - Nat. Vicentina 10 (2006): 5-74.

D’Antraccoli, M., Angiolini, C., Bonari, G., De Bellis, A., Fontana, D., Liguori, P., Peruzzi, L., Roma-Marzio, F. \& Bedini, G. 2016: La prima volta di Wikiplantbase \#Toscana in campagna. - Not. Soc. Bot. Ital. 0: 15-16.

Lucarini, D., Gigante, D., Landucci, F., Panfili, E. \& Venanzoni, R. 2015: The anArchive taxonomic Checklist for Italian botanical data banking and vegetation analysis: theoretical basis and advantages. - Pl. Biosyst. 149(6): 958-965. doi:10.1080/11263504.2014.984010

Peruzzi, L. 2010a: Checklist dei generi e delle famiglie della flora vascolare italiana. - Inform. Bot. Ital. 42(1): 151-170. 
- 2010b: Segnalazioni floristiche per le regioni italiane 2005-2010: una prima analisi dei dati a 5 anni dalla pubblicazione della Checklist della flora vascolare italiana. - Pp. 9-10 in: Peccenini, S., Domina, G. \& Salmeri, C. (Eds.): La biodiversità vegetale in Italia: aggiornamenti sui gruppi critici della flora vascolare. Roma, 22-23 October 2010.

— \& Bedini, G. (Eds.) 2015 onwards: Wikiplantbase \#Toscana v. 2.1. - Available from: http://bot.biologia.unipi.it/wpb/toscana/index.html (accessed 1 June 2016).

—, Bagella, S., Filigheddu, R., Pierini, B., Sini, M., Roma-Marzio, F., Caparelli, K. F., Bonari, G., Gestri, G., Dolci, D., Caria, M. C., Marrosu, M., D’Antraccoli, M. \& Bedini, G., 2015: Wikiplantbase: a collaborative platform for floristic data. First steps towards Italian regional floras online. - P. 147 in: Anonymous (Eds.) II International Plant Science Conference - $110^{\circ}$ Congresso della Società Botanica Italiana, 14-17 September 2015, Pavia, Italy.

Pierini, B. \& Peruzzi, L. 2014: Prodromo della flora vascolare della Provincia di Lucca (Toscana nord-occidentale). - Inform. Bot. Ital. 46(1): 1-499.

Scoppola, A. \& Magrini, S. 2005: Floristic references: a 1950-2005 database. in: Scoppola, A., Blasi, C. (Eds.), Stato delle conoscenze sulla flora vascolare d'Italia. CD-ROM attached. - Roma,

The Angiosperm Phylogeny Group, 2016: An update of the Angiosperm Phylogeny Group classification for the orders and families of flowering plants: APG IV. - Bot. J. Linn. Soc. 181(1): 120. doi:10.1111/boj.12385.

Thiers, B., 2007-onwards: Index Herbariorum: A global directory of public herbaria and associated staff. New York Botanical Garden's Virtual Herbarium. http://sweetgum.nybg.org/science/ih (accessed 1 June 2016).

Addresses of the authors:

Lorenzo Peruzzi ${ }^{1}$, Simonetta Bagella ${ }^{2}$, Rossella Filigheddu ${ }^{2}$, Brunello Pierini ${ }^{3}$, Maria Sini ${ }^{4}$, Francesco Roma-Marzio ${ }^{1}$, Katia Francesca Caparelli ${ }^{5}$, Gianmaria Bonari $^{6}$, Giovanni Gestri ${ }^{7}$, David Dolci ${ }^{1}$, Angela Consagra ${ }^{1}$, Patrizia Sassu ${ }^{8}$, Maria Carmela Caria ${ }^{2}$, Giovanni Rivieccio ${ }^{9}$, Marco Marrosu ${ }^{10}$, Marco D’Antraccoli ${ }^{1}$, Giuliano. Pacifico ${ }^{11}$, Valeria Piu ${ }^{12} \&$ Gianni Bedini ${ }^{1}$,

${ }^{1}$ Dipartimento di Biologia, Università di Pisa, Italy, e-mail: lorenzo.peruzzi@unipi.it. ${ }^{2}$ Simonetta Bagella, Rossella Filigheddu, Maria Carmela Caria, Dipartimento di Scienze della Natura e del Territorio, Università di Sassari, Italy, e-mail: bage@uniss.it.

${ }^{3}$ via Zamenhof 2, 56127 Pisa, Italy.

${ }^{4}$ Strada Vicinale Li Giosi Nobi 6, 07100 Sassari, Italy.

${ }^{5}$ P.za G. Guerra 28, 50053 Empoli, Italy.

${ }^{6}$ Dipartimento di Scienze della Vita, Università di Siena, Italy.

${ }^{7}$ via Bonfiglioli 30, 59100, Prato, Italy.

${ }^{8}$ Via Amundsen 6, 07100 Sassari, Italy.

${ }^{9}$ Via Balai 72, 07046 Porto Torres, Italy.

${ }^{10}$ SC Platamona 32, 07100 Sassari, Italy.

${ }^{11}$ via Ponte del Vescovo 32/D, 54100 Massa, Italy.

${ }^{12}$ Via Regione Salighes snc, 07014 Ozieri, Italy. 
